\title{
VIABILIDADE DA IMPLEMENTAÇÃO DO CUSTEIO BASEADO NAS ACTIVIDADES (CBA) NOS DIVERSOS SECTORES DE ACTIVIDADE
}

\section{Conceição Gomes*}

\begin{abstract}
O custeio tradicional apresenta diversas limitações devido às grandes mudanças que se têm verificado, tais como: aumento dos custos fixos, diversificação dos produtos, crescimento da competitividade. Para combater estas limitações, surge o custeio baseado nas actividades (CBA) no sector da indústria. Contudo, numa empresa têm de existir determinadas condições para que se torne possivel a implementação do CBA.

Surge-nos, então, a questão: $O$ CBA será viável em todas as empresas do sector da indústria, dos serviços e do comércio? Comparando os diversos sectores verificamos que têm características diferentes. Convém salientar, que o mesmo acontece entre empresas dum mesmo sector.

Depois de uma revisão da literatura apurámos que a questão da viabilidade do CBA não depende do sector onde a empresa está inserida.
\end{abstract}

Palavras-Chave: custeio baseado nas actividades, contabilidade de gestão, gastos gerais de fabrico, sectores de actividade.

Due to great changes that have been taking place, the traditional costing presents several limitations, such as: increase of fixed costs, product diversification and growing competitiveness. To overcome these limitations, the activity-based costing $(A B C)$ comes up in the industry sector. Nevertheless, some conditions are required so that the $A B C$ can be implemented in companies.

It raises the following question: Will $A B C$ be feasible in every company from industry, service and trade sectors? Comparing these sectors, different characteristics among them can be seen. It is important to notice that the same happens among companies, which belong to the same sector.

* Escola Superior de Ciências e Tecnologia - Pólo da Figueira da Foz - Universidade Católica Portuguesa 
After having reviewed bibliography, it can be concluded that the feasibility of $A B C$ doesn't depend on the sector in which the company is implemented.

Key words: activity-based costing, management accounting, factory overhead, activity sector.

\section{INTRODUÇÃO}

Ao observarmos, nos nossos dias, as empresas e o contexto onde estão inseridas, verificamos que tudo é muito diferente do que se passava a algumas décadas atrás. Visto que actuamos num mercado global e mais competitivo, é exigida mais informação para a tomada de decisão. A nível interno temos novas tecnologias e diversidade na produção em vez de produções em grande escala. Tudo isto afecta a estrutura de custos das empresas. Os custos são cada vez mais indirectos em detrimento dos directos, ou seja, aumentam os custos de investigação e desenvolvimento, desenho, distribuição e logística.

Aparecem, assim, novos métodos de custeio entre os quais o custeio baseado nas actividades (CBA), método que se baseia nas actividades para a afectação dos custos. Os custos são acumulados nas actividades e depois através de uma grande variedade de indutores de custo são imputados aos objectos de custo.

O CBA teve origem no sector da indústria. Neste sector, as empresas sempre utilizaram sistemas de custeio para a valorização dos seus inventários. Quando verificaram que não estavam a obter respostas viáveis, apelaram por um novo método de afectação de custos.

Todavia, podemos questionar se o CBA é viável em todas as empresas do sector da indústria, como também nas empresas pertencentes ao sector dos serviços e do comércio. As empresas do sector dos serviços têm características específicas, como por exemplo: a maior parte dos custos são indirectos e fixos, os produtos/serviços são intangíveis, há uma diversidade de objectos de custo, etc. Porém, convém salientar que as empresas do sector de serviços estão cada vez mais inseridas num ambiente competitivo necessitando de um método de custeio que as ajude a sobreviver. Por sua vez, as empresas do sector do comércio caracterizam-se por não serem problemáticas no que respeita ao custo das mercadorias. Será que é viável incorrer em custos elevados e implementar o CBA em empresas deste sector? Convém não esquecer de que nestas empresas cada vez mais aparecem custos indirectos como por exemplo: marketing, distribuição e logística, os quais deverão ser imputados às mercadorias, ou, até mesmo ao cliente.

São questões que pretendemos dar resposta através de uma revisão da literatura. 


\section{BREVE CARACTERIZAÇÃO DO CBA}

Segundo Cooper (1989), cada vez mais os sistemas de contabilidade de custos dão uma informação débil aos gestores. Ou seja, o custo atribuído aos produtos é incorrecto e a informação fornecida é irrelevante para a tomada de decisão. No fundo, os sistemas de custeio estão a ficar obsoletos. Cooper e Kaplan (1988) referem que muitas empresas detectam os problemas depois de terem perdido a sua competitividade e a sua rendibilidade ter diminuído. Como se pode detectar a obsolescência dos sistemas de custeio?

Cooper (1989) identifica vários sinais que indicam que é melhor analisar o sistema de custeio. Estes manifestam-se ao longo de vários anos, como por exemplo: o desejo dos gestores funcionais em eliminar linhas de produção rentáveis, explicação difícil das margens elevadas, os produtos complexos têm margens altas, diversos departamentos começam a desenvolver o seu próprio sistema de custeio, o departamento de contabilidade despende imenso tempo em projectos especiais, os preços dos concorrentes são baixos, melhoria na tecnologia, etc.

Para Horngren et al. (2000), CIMA (1993), Cooper e Kaplan (1988) e King et al. (1994) se o sistema de custeio estiver obsoleto devemos introduzir o CBA.

Innes e Mitchell (1998) referem que o CBA difere de um sistema de custeio tradicional devido ao tratamento que dá aos gastos gerais que não estão relacionados com o volume de produção.

Segundo Cooper e Kaplan (1988), o CBA é desenhado para fornecer informação mais correcta acerca das actividades de produção e manutenção e custos dos produtos. Ajuda os gestores a tomarem melhores decisões acerca do desenho dos produtos, fixação de preços, marketing e melhorias ao nível das operações.

Para Sutton (1991), o CBA está sob o pressuposto de que as actividades consomem os recursos e os produtos consomem as actividades. Os custos são relacionados com os produtos através das actividades desempenhadas nos mesmos.

Por sua vez, Maher et al. (1997) diz que o CBA é uma ferramenta utilizada na gestão baseada nas actividades em que primeiro se distribuem os custos pelas actividades e a seguir a imputação dos custos aos produtos é realizada de acordo com a sua utilização das actividades. Refere, ainda, que existem controvérsias acerca do CBA onde se refere que o CBA é um prolongamento do método dos centros de custos. Porém, o CBA fornece informação muito mais detalhada. 
Gering (1999) foca o aspecto do CBA ser uma ferramenta poderosa para fomentar a transparência numa empresa e quantificar o impacte dos factores externos.

Segundo Shapiro (1999), o CBA é uma nova aproximação da contabilidade de gestão para determinar correctamente o custo dos produtos e clientes,.

Para Horngren et al. (2000), o CBA caracteriza-se na acumulação dos custos nas actividades de uma organização, seguindo-se a aplicação desses custos aos produtos/serviços.

\subsection{Actividades}

Segundo Horngren et al. (2000), uma actividade é um acontecimento, tarefa ou unidade de trabalho com um objectivo específico. Para Brimsom e Antos (1994), Abrahams e Reavely (1998), uma actividade é uma sequência de acontecimentos que converte "inputs" em "outputs" através da utilização de recursos.

Ao implementarmos o CBA numa empresa, uma das primeiras tarefas é a identificação das actividades.

Brimsom e Antos (1994) classificam as actividades em repetitivas e não repetitivas, principais e secundárias. As repetitivas são realizadas para todos os "outputs" e as não repetitivas são actividades adicionais visto que são desempenhadas apenas em certos "outputs". As primárias contribuem directamente para a missão da empresa enquanto que as secundárias são actividades gerais, tais como: administração, supervisão, etc. Atkinson et al. (2001), também, classificam as actividades em eficientes e ineficientes. As eficientes não consomem recursos em excesso, enquanto que as ineficientes requerem mais recursos para produzir o desejado "output".

$\mathrm{Na}$ identificação de actividades devemos seguir algumas regras, nomeadamente: devem ser constituídas por um verbo, objectivo e substantivo, devem ter um "output" homogéneo, tipicamente são realizadas por uma pessoa, devem representar um nível significativo de gastos, devem suportar um processo de gestão, devem ignorar os serviços de uma empresa na definição das actividades e devem possuir a característica da simplicidade, Brimsom e Antos (1994).

Para Cooper e Kaplan (1998), a identificação das actividades termina com a elaboração de um dicionário de actividades. Este é constituído por uma listagem de actividades e pela descrição de como são desempenhadas. 


\subsection{Hierarquia dos custos}

Para Cooper (1990, p. 7)), o CBA “identifica e classifica as actividades dum sistema produtivo em quatro categorias: nível unidade, nível lote, nível manutenção do produto (product-sustaining) e nível manutenção da empresa (facility-sustaining). Os custos das três primeiras categorias de actividades são distribuídos aos produtos usando os indutores de custos que captam o comportamento dos custos que estão a ser distribuídos. Os custos do nível de manutenção da empresa são tratados como custos do período ou são distribuídos ao produto de maneira arbitrária."

King et al. (1994), Horngren et al. (2000), também, abordam a hierarquização das actividades, a qual transmite os graus de dificuldade em determinar a relação causa-efeito. No nível unidade, os recursos são sacrificados em actividades desempenhadas a cada unidade produtiva ou serviços. No nível lote, os recursos são sacrificados em actividades que estão relacionadas com um grupo de unidades produzidas. No nível de manutenção do produto, os recursos são sacrificados em actividades que são utilizadas para suportar produtos ou serviços individuais. Não existe qualquer relação com a unidade ou lote. No nível de manutenção da empresa, os recursos são sacrificados em actividades, mas, não podem ser imputados aos produtos ou serviços individualmente, pois são suportados pela organização num todo. É difícil estabelecer uma relação causa-efeito com os produtos ou serviços.

É de salientar que Atkinson et al. (2001) acrescentam mais um nível à hierarquia de actividades, o nível manutenção do cliente. Se nos deslocarmos para a área de marketing e vendas encontramos actividades que estão relacionadas com os clientes, mas que são independentes do volume de produção/serviços.

\subsection{Contributo do CBA}

Segundo Chan (1993), o CBA dá diversos contributos às empresas: é mais exacto não só quando há diversidade dos "outputs", mas também quando existem muitos gastos gerais que não estão relacionados com o volume de produção; gera mais informação ao nível dos custos de produção, assim os gestores estão mais aptos a tomar melhores decisões a nível da fixação do preço como também no abandono e introdução de produtos e serviços; auxilia os gestores na implementação de novas estratégias tais como identificar as linhas de produção mais rentáveis e estabelecer preços competitivos; ajuda na redução dos custos, identificando as actividades que não adicionam valor, as quais num futuro próximo deverão ser eliminadas. 
Lucey (1996) apresenta os seguintes contributos: os custos dos produtos estão mais aproximados da realidade, principalmente, nas indústrias de tecnologia avançada cujos gastos gerais são uma porção significativa dos custos industriais; mais gastos gerais podem ser imputados aos produtos; o CBA reconhece quais as actividades que consomem recursos e quais os produtos que utilizam as actividades; o CBA foca a sua atenção no comportamento real dos custos ajudando a sua redução, eliminando as actividades que não adicionam valor ao produto; o CBA reconhece a complexidade e diversidade da produção moderna utilizando múltiplos indutores de custos; consegue prever o custo variável do produto a longo prazo o que é importante para a tomada de decisões estratégicas; é flexível para determinar custos de qualquer coisa; fornece medidas financeiras muito úteis.

Innes e Norris (1997) referem que a aplicação do CBA permitiu um melhoramento a nível de conteúdo dos custos, recursos de gestão principalmente a nível de recursos humanos, validação de propostas e decisões, selecção de actividades, redesenho do processo e comunicação a todos os níveis. Mas, não quer dizer que qualquer aplicação implicará estes melhoramentos, pois depende da maneira como o CBA é utilizado.

Para Sutton (1991), o CBA permite a quem faz o desenho dos produtos perceber o impacte de diferentes desenhos no custo dos produtos. Leva a que as actividades das empresas sejam mais rentáveis.

King et al. (1994) refere ainda que o CBA pode ser dirigido a várias áreas da contabilidade de gestão, por outras palavras, não trás só benefícios no custeio dos produtos. O CBA fornece uma boa base para a orçamentação dos gastos gerais de fabrico o que vem, por outro lado, melhorar o controlo de gestão. Disponibiliza uma nova perspectiva dos custos permitindo uma melhor análise e redução de custos assim como melhorias no processo. Confere, também, um aperfeiçoamento na avaliação de desempenho visto que incide na utilização dos recursos e quantifica o "output" por actividade implicando uma melhoria em termos de "feedback" para o controlo de gestão. Em relação ao desenho dos produtos, o CBA mostra com clareza e detalhe várias alternativas à afectação do seu custo. Finalmente, melhora a análise do comportamento dos custos e aperfeiçoa a análise da rendibilidade dos clientes.

Para Mabberley (1998), o CBA é uma técnica que fornece uma análise da utilização dos recursos mais detalhada e que a maior parte dos custos operacionais desta técnica são de pessoal. Tem como vantagem proporcionar ao gestor uma melhor informação acerca de como os funcionários empregam o seu tempo e de quais os factores que causam variação dos custos. 


\subsection{Condições para a implementação do CBA}

Para implementarmos o CBA têm de verificar-se determinadas condições numa empresa.

Chan (1993) refere que é necessário avaliar a empresa em termos económicos e técnicos, ou seja, temos de apurar se os benefícios de implementar o CBA são maiores que os custos, e, se é viável a identificação das actividades que consomem os recursos.

Chan (1993) refere a existência de dois tipos de custos associados com qualquer sistema de custeio: custos de medidas e custo dos erros. Os custos de medidas incluem os custos de obtenção da informação e os custos de computação. Os custos de medidas são mais altos com o CBA do que com o antigo sistema, visto que o CBA necessita de mais indutores de custo, logo é necessário mais esforços na reunião de informação, bem como no seu tratamento. Os custos dos erros incluem o custo de fabricar um produto de má qualidade, um péssimo investimento em capital e incorrectas decisões orçamentais. Os custos dos erros são maiores nos sistemas antigos do que no CBA, porque a informação é menos correcta. O CBA deverá ser somente implementado quando a diminuição do custo dos erros exceder o aumento do custo das medidas. De facto, o CBA fornece maiores benefícios às empresas que enfrentam uma grande concorrência porque neste caso o custo dos erros no sistema antigo é muito grande.

Para implementar o CBA também é necessário um estudo detalhado das organizações, para que se possa conduzir uma análise de actividades de modo a identificar as actividades que consomem recursos. Por vezes, é difícil e muito morosa a identificação e relacionamento dos recursos consumidos das actividades por causa das complexidades envolvidas. Sendo assim, é inexequível a implementação do CBA para algumas organizações.

Segundo Krupnicki e Tyson (1997), uma empresa que pretenda implementar o CBA deve fornecer recursos suficientes como também as pessoas envolvidas no projecto deverão observar bem quais são realmente os indutores de custo a utilizar (observando actividades, entrevistando os empregados, desenvolvendo métodos quantitativos tais como análises de regressão). Se uma empresa não fornece os recursos necessários, de certeza que ficará desapontada com os resultados.

Segundo Sá e Jorge (1998), para que a implementação do CBA tenha sucesso será necessário o empenho da gestão de topo de modo a que todos os objectivos estejam em concordância, que o CBA esteja relacionado com a estratégia, qualidade e avaliação de desempenho, consciência do tempo que é necessário para esta implementação e experiência em meios informáticos. 
"Cooper e Kaplan (1998) estabelecem duas regras que definem em que tipo de empresas é que o CBA terá mais impacte, por outras palavras, quando é que as empresas terão benefícios na sua implementação.

A regra "Willie Sutton rule" define que devemos aplicar o CBA nas áreas com grandes gastos gerais indirectos e com muitos recursos de manutenção, principalmente, quando estas despesas têm tendência a crescer. Quando todos os custos são referentes a materiais directos e mão-de-obra directa, quer dizer que estão relacionados directamente com os produtos, sendo o CBA desprezível, pois o custeio tradicional é suficiente. Se todas as actividades forem do tipo unidade os dois sistemas de custeio dão respostas equivalentes.

A regra "high-diversity rule" define que é para procurar uma situação onde exista grande diversidade de produtos, clientes e processos." (Gomes e Rodrigues, 2003:4)

De acordo com a regra de "Willie Sutton", Vokurka e Lummus (2001) realizaram um estudo de modo a verificar qual a percentagem de gastos gerais de fabrico a partir do qual o CBA deveria ser implementado.

“com gastos gerais de fabrico (GGF) à volta dos $15 \%$ ou mais em relação ao custo total, parece que o CBA seria benéfico. Para níveis inferiores a $15 \%$ uma análise custo benefício seria apropriada para investigar com maior profundidade os benefícios da implementação nessa situação específica." (Vokurka e Lummus, 2001:47)

Innes e Mitchell (1998) focam diversos factores que podem influenciar a implementação do CBA, os quais poderão ser internos ou externos. Como externos temos o aumento de competitividade e o desenvolvimento da tecnologia de produção. Como internos temos a recepção dos trabalhadores ao CBA, mudança nos métodos de produção, deficiência na contabilidade corrente e disponibilidade de recursos.

Em resumo, através de uma revisão de literatura, verificámos que numa empresa têm de existir diversas condições para que seja viável a implementação do CBA. Sumariamente, temos: gastos gerais de fabrico elevados; grande diversidade de produtos, clientes e processos; empenho da gestão de topo; disponibilidade em meios informáticos; grande competitividade; o custo de medidas inferior ao custo dos erros, etc.

Será que o CBA é viável em todos os sectores? Nos pontos seguintes realizaremos uma pequena análise para testar a viabilidade do CBA no sector da indústria, no sector dos serviços e no sector do comércio. 


\section{O CUSTEIO BASEADO NAS ACTIVIDADES NO SECTOR DA INDÚSTRIA}

\subsection{Breve caracterização das empresas do sector da indústria}

As empresas do sector da indústria caracterizam-se pela transformação das matérias-primas em produtos acabados, através da aplicação de mãode-obra directa e gastos gerais de fabrico. Os "stocks" destas empresas são constituídos por: produtos acabados, produtos em curso de fabrico, matérias-primas, matérias subsidiárias, materiais diversos, etc.

Segundo Horngren et al. (2000), as empresas do sector da indústria disponibilizam aos seus clientes produtos tangíveis que foram obtidos através da transformação de diversos materiais.

As empresas do sector da indústria são

"unidades económicas que reunindo e combinando todos os factores necessários à realização de determinado processo técnico de produção, transformam, por via física ou química, matérias orgânicas ou inorgânicas em produtos mais próximos da sua utilização final." Silva (1991, p. 9)

"Das operações industriais, que variam evidentemente de indústria para indústria, resultam, umas vezes, simples alteração de forma ou de aspecto e outras vezes, modificação completa das características físicas ou químicas das matérias trabalhadas" (Silva, 1991:23)

Segundo Silva (1991), desde sempre, nestas empresas tornou-se necessário complementar a contabilidade geral com a contabilidade industrial. Como por exemplo, a necessidade de valorizar os produtos acabados que estavam em armazém, fez com que se desenvolvesse algumas técnicas para o apuramento do custo do produto.

Para Atkinson et al. (2001), nestas últimas décadas, a estrutura dos custos de produção tem sofrido modificações profundas, ou melhor, a mão-de-obra directa é cada vez mais baixa, normalmente cerca de $5 \%$ do custo de produção. Por outro lado os custos indirectos de produção aumentaram drasticamente visto que as matérias-primas mantêm a mesma proporção.

\subsection{Viabilidade do CBA no sector da indústria}

Muitos autores focam vários factores que causam problemas no custeio tradicional, mais concretamente, nas empresas do sector industrial.

Segundo Kaplan (1986), as empresas do sector da indústria estão a sofrer grandes mudanças a nível dos processos produtivos, quer em termos tecnológicos quer no aspecto organizativo. Observando algumas empresas verificámos que algo se mantém constante, que é a 
contabilidade de gestão. A contabilidade de gestão não informa, não auxilia, não controla os actuais processos produtivos. O sistema de custeio é obsoleto, é necessário um sistema de custeio que considere um novo conjunto de medidas, agregação e distribuição que estão disponíveis nos novos processos produtivos. $\mathrm{O}$ que mostra um ambiente propício à viabilidade do CBA na indústria.

Howeel e Soucy (1987) referem que o sector da indústria tem sofrido grandes mudanças e verificou-se a criação dum novo ambiente industrial através de: qualidade mais alta, "stock " mais baixo, automação, utilização de informação tecnológica. Estes aspectos implicam a necessidade de um sistema de custeio compatível. Se analisarmos os custos de produção, estes são apenas uma parte dos custos totais de uma empresa. Existe a engenharia, marketing, contabilidade e gestão geral, que também são fundamentais para a fabricação dos produtos.

Segundo Plossl (1990), a evolução do planeamento e controlo de produção e seus processos produtivos têm transformado a contabilidade de custos tradicional numa ferramenta obsoleta e perigosa. Actualmente, os mercados e as tecnologias modificam-se, rapidamente, implicando maiores mudanças no desenho do produto e constantes mudanças no processo produtivo.

Temos CIMA (1993) indicam vários factores que causam problemas ao custeio tradicional: enormes custos fixos, pouca mão-de-obra directa, grande mudança tecnológica, diminuição dos custos da contabilidade, aumento da diversidade dos produtos, crescimento da concorrência e incremento da desregulamentação.

Cooper e Kaplan (1988) e Plossl (1990) mencionam que hoje em dia os custos de mão-de-obra são cada vez mais diminutos e, em contrapartida, são maiores os custos relacionados com a manutenção, distribuição e desenho dos produtos, os quais são difíceis de distribuir. É necessário um sistema de custeio eficaz, ou seja, capaz de identificar e distribuir os custos indirectos aos produtos.

De acordo com todos estes factores, torna-se premente a viabilidade do CBA no sector da indústria. Tanto é que o CBA apareceu e desenvolveu-se no sector da indústria porque as empresas deste sector tiveram necessidade de aplicar novas técnicas para o apuramento do custo do produto.

Contudo, Rotch (1990) refere que em relação ao sector da indústria existem empresas que têm condições para implementar o CBA e outras não.

Observando o sector da indústria, em termos de estrutura de custos, verificámos numa análise realizada por Gomes e Rodrigues (2003) que os gastos gerais estão entre os $17.55 \%$ e os $84.14 \%$. Um intervalo alargado. 
Só mostra que existem diversos tipos de actividades económicas dentro do sector da indústria.

Tendo em conta o número de utilizações e o seu sucesso, podemos afirmar que é no sector industrial que o CBA está a ser mais utilizado.

No estudo que Khoury e Anceleviez (1999) realizaram no Brasil, as empresas que utilizam mais CBA pertencem ao sector da indústria.

No estudo realizado por Duarte (2002), em Portugal verificou-se que cinco empresas estão a utilizar o CBA, três destas pertencem ao sector da indústria.

No estudo realizado na Nova Zelândia por Cotton et al. (2003) também mostra que o sector industrial é o que possui uma maior percentagem de empresas a utilizar o CBA.

Innes e Mitchell (1989) referem alguns sectores em que já foi aplicado o CBA: controlos pneumáticos, colchetes para roupa, banca de retalho, engenharia, distribuição de energia eléctrica, fabricação de papel, testes electrónicos e instrumentos de medição, engenharia eléctrica, quadros de circuito electrónico e produção de vidro. A maior parte pertence ao sector da indústria.

Também no estudo de Cobb et al. (1992) a maior parte das empresas que utilizam o CBA pertencem ao sector da indústria.

Só demonstra que o sector da indústria foi o pioneiro na aplicação do CBA.

O CBA apareceu primeiro nas empresas industriais porque estas já usavam sistemas de custeio para valorizar os seus inventários. Por isso, quando os sistemas passaram a estar obsoletos de acordo com as mudanças nos produtos, clientes e processos de negócio, trataram de modificar o sistema.

Considerando os diversos estudos podemos afirmar que a utilização do CBA é não só viável no sector da indústria, como produz informação relevante para a tomada de decisão.

\section{O CUSTEIO BASEADO NAS ACTIVIDADES NO SECTOR DOS SERVIÇOS}

\subsection{Breve caracterização das empresas do sector dos serviços}

Em termos gerais, as empresas do sector dos serviços fornecem serviços ou produtos intangíveis aos seus clientes, por outras palavras, desempenham trabalho para outros.

Para Lambert e Whiworth (1996), na década de 90, a distinção entre empresas industriais e empresas de serviços tornou-se confusa. 
Segundo Rotch (1990), as empresas de serviços têm várias características distintas tais como: o "output" é muitas vezes difícil de definir, a actividade relacionada com os serviços é menos previsível e os custos conjuntos são uma grande percentagem do custo total, pelo que se torna difícil a ligação do "output" com as actividades.

Já Maher et al. (1997) e Atkinson et al. (2001) referem que as empresas de serviços não produzem, antecipadamente, os serviços para os ter em "stock" há, sim, uma entrega em tempo real, logo as imperfeições são difíceis de detectar antes de serem notadas pelos clientes. Daqui podem resultar consequências desastrosas, como por exemplo a troca por outra empresa concorrente. No fundo, os produtos/serviços são muito sensíveis com o tempo e com a qualidade, contudo, os fluxos dos custos nas empresas de serviços são semelhantes às empresas industriais.

Atkinson et al. (2001) acrescentam ainda que os custos das empresas do sector dos serviços são indirectos e fixos. Têm poucos materiais directos e, por vezes, até não existem. Em relação à mão-de-obra é difícil estabelecer uma relação directa com um determinado serviço ou com um determinado cliente. Logo, verificamos que as empresas de serviços não têm, praticamente, custos directos para servirem de base de imputação. As empresas de serviços têm uma grande componente de custos fixos porque necessitam de adquirir os seus recursos antecipadamente para poderem servir os seus clientes. As flutuações na procura não influenciam a aquisição de recursos. Analisando, pormenorizadamente, verificamos que o custo variável de um serviço poderá ser igual a zero.

Cooper e Kaplan (1998) concordam dizendo que o custo marginal de fornecer mais um serviço ou atender mais um cliente é aproximadamente zero, não afecta os custos. Se considerarmos o custo marginal para apurar o preço, diríamos que este seria próximo de zero.

Atkinson et al. (2001) referem, também, que as empresas de serviços, muito mais que as do sector industrial, devem dar muita atenção aos clientes porque o seu comportamento influencia os custos operacionais do produto/serviço. As empresas de serviços necessitam de identificar a rendibilidade de cada cliente, pois mesmo que os produtos/serviços sejam "standard" o custo poderá ser diferente.

Para Cooper e Kaplan (1998), nas empresas de serviços há uma completa separação na tomada de decisão que diz respeito às receitas dos clientes e à que está relacionada com o investimento em recursos. As empresas de serviços querem saber o custo dos produtos/serviços e dos clientes, para: gerir os produtos e clientes, determinar o canal de distribuição dos serviços aos clientes e orçamentar a aquisição de recursos da organização. 
Viabilidade da implementação do custeio baseado nas actividade (CBA)

\subsection{Viabilidade do CBA no sector dos serviços}

"analisámos os subsectores mais propensos à aplicação do CBA, os que possuem as percentagens mais altas de gastos gerais. Apurámos que todos pertencem ao sector de serviços. As actividades pertencentes a este sector são as que têm mais custos indirectos e uma diversidade de serviços." (Gomes e Rodrigues, 2003:13)

Lambert e Whiworth (1996) apresentam algumas críticas às empresas de serviços que utilizam o custeio tradicional, como por exemplo: os custos não são conhecidos no presente, não há uma base racional para as decisões de preços, não sabemos quantos "mix" de serviços oferecem, não estamos informados de qual é a mistura de recursos utilizada, não é conhecida a eficácia dos recursos, não há relação das actividades com limitações orçamentais e não há esquemas de medidas de desempenho.

Para Atkinson et al. (2001) e Kaplan e Cooper (1998), o sector de serviços aplicou o CBA posteriormente ao sector da indústria, porque o seu meio envolvente não era tão competitivo, não havendo, deste modo, grande exigência na informação. As empresas de serviços durante largos anos não possuíam sistemas de custeio, visto não existir nenhuma necessidade (estabelecida) para medir o custo dos serviços e clientes. Também, não havia grande concorrência nesses mercados, por exemplo muitas empresas eram públicas (telecomunicações, electricidade, só mais tarde é que começaram a ser privatizadas), não tinham necessidade em saber o custo por serviços e por cliente, possuindo uma informação financeira muito simples. Com a abertura dos mercados e a privatização de muitas empresas, as necessidades passaram a ser outras. Na prática, o modelo $\mathrm{CBA}$ aplica-se inteiramente às empresas do sector dos serviços. Tendo em conta as características do CBA, podemos afirmar que apesar deste ter nascido no sector da indústria é no sector dos serviços que encontra um amplo campo de aplicação. Ao analisar o sector da indústria, verificámos que o CBA incidia na distribuição dos custos indirectos, ou seja, mais na parte dos serviços da empresa, como por exemplo desenho, manutenção, inspecção, logística, etc. Não dava atenção aos materiais directos nem à mão-de-obra directa. Logo, as empresas de serviços são candidatas fortes ao CBA. No fundo, estamos perante um alargamento às empresas de serviços não envolvendo novos princípios. As empresas de serviços necessitam do CBA para relacionar os custos dos recursos utilizados com os produtos/serviços e clientes. Como a maior parte das empresas de serviços têm muitos custos fixos e indirectos necessitam mais do CBA para a distribuição dos custos a nível interno que as industriais. No fundo, verificamos que as empresas de serviços não podem utilizar os custos directos como indutor de custo. 
"Embora esteja disponível menos informação acerca da utilização do CBA no contexto dos serviços, o que existe sugere que o CBA pode ser aplicado com sucesso nas empresas de serviços usando as mesmas ferramentas adoptadas nas empresas industriais." (King et al., 1994:10)

Chan (1993) defende que o CBA é um método desenhado para custear produtos ou serviços com mais exactidão. Tem sido implementado com sucesso em várias empresas de serviços tendo a gestão uma opinião favorável a seu respeito.

Baxendale (2001) apresenta as empresas de serviços como as mais problemáticas no custeio do produto/serviço. A principal razão é a impossibilidade de inventariação do produto/serviço. Outra razão é que a maior parte dos custos são fixos, não se identificam facilmente com cada serviço. Logo, a solução seria a aplicação do CBA.

King et al. (1994) concordam que é muito difícil definir o objecto de custo numa empresa de serviços. Logo, torna-se complicado a selecção dos indutores de custo. Os serviços poderão ter vários elementos intangíveis tais como a velocidade de entrega, o grau de conforto, etc. Deste modo, qualquer objecto de custo poderá incorporar vários elementos, os quais poderão ter por detrás várias actividades que originam custo. Segundo King et al. (1994), normalmente nas empresas de serviços é utilizado o custeio por obra, isto é, temos diversas prestações de serviços isoladas o que implica a existência de um conjunto de informação acerca dos indutores de custo para cada serviço, de modo a que se possa custeá-los.

Em suma

"O CBA pode ser aplicado com sucesso em algumas empresas de serviços. Fornece um esquema analítico que pode ser útil até mesmo em situações onde hoje seria impraticável a quantificação e afinidades de custos." (Rotch, 1990:13)

Através da revisão de literatura analisámos já vários casos de sucesso no sector dos serviços, como por exemplo: telecomunicações, financeiro, saúde, etc. Podemos referir que em Portugal, segundo Duarte (2002) no sector das telecomunicações temos duas empresas a utilizar o CBA e, segundo Vieira (2002), foi implementado num banco. 


\section{O CUSTEIO BASEADO NAS ACTIVIDADES NO SECTOR DO COMÉRCIO}

\subsection{Breve caracterização das empresas do sector do comércio}

O sector do comércio caracteriza-se pelas empresas adquirirem aos fornecedores produtos já na forma acabada, ou seja, mercadorias e vendê-las sem qualquer transformação aos clientes. Estas empresas possuem "stock" de mercadorias.

"No comércio, os estoques ou existências em armazém são constituídos pelas várias mercadorias que as empresas compraram e ainda não revenderam." (Silva, 1991:11)

Estamos num ambiente competitivo sendo cada vez mais desafiante e difícil. As empresas solicitam diferentes e melhores informações de contabilidade de gestão.

Isto também acontece nas empresas do sector do comércio que cada vez mais necessitam de informação acerca dos canais de distribuição, “marketing”, logística e rendibilidade de clientes.

\subsection{Viabilidade do CBA no sector do comércio}

Segundo Horngren et al. (2000) a finalidade de aplicação do CBA a este sector está relacionada com a rendibilidade das diversas linhas de produtos. Os gestores deste tipo de empresas acreditam que as percentagens de rendibilidade do custeio baseado nas actividades fornecem informações reais para a colocação dos produtos nas prateleiras, ou seja, para decidir quais os produtos que devem ser destacados.

Gomes e Rodrigues (2003) realizaram um estudo de modo a analisar quais as actividades económicas com tendência a aplicar o CBA, utilizando a regra de "Willie Sutton" e o estudo de Vokurka e Lummu (2001).

"Considerando a percentagem dos $15 \%$, verificamos que apenas três actividades se encontram abaixo desta percentagem: comércio a retalho de combustíveis para veículos a motor, comércio por grosso de produtos agrícolas brutos e animais vivos, comércio de veículos automóveis. Segue-se com $16,82 \%$ o comércio por grosso de produtos alimentares, bebidas e tabaco. Todas estas actividades pertencem ao sector do comércio, e, segundo Vokurka e Lummus (2001) será necessário uma análise mais cuidada para verificar a aplicabilidade do CBA. Convém referir, que existem alguns casos de estudo em que o CBA foi aplicado em empresas comerciais. A máxima percentagem de gastos gerais que encontramos numa actividade comercial é de 37,56\%. Isto é compreensível, visto que os custos de transformação numa empresa comercial são baixos. Os gastos gerais dizem respeito a custos 
administrativos, distribuição e financeiros. O custo das mercadorias é conhecido, o problema é a atribuição dos custos não industriais aos produtos, como por exemplo de distribuição" (Gomes e Rodrigues, 2003:11)

Poderíamos questionar a sua viabilidade no sector do comércio.

Segundo Atkinson et al. (2001) neste sector existem custos que merecem ter um cuidado especial: marketing, distribuição, distribuição de catálogos, serviço de clientes, custos de armazenagem e transporte até ao cliente.

Lewis (1991) refere que nalguns produtos a maior causa do seu alto custo é a distribuição e outras funções de marketing. O CBA pode ser aplicado de modo a relacionar os custos de marketing às linhas de produtos e territórios de modo a medir a rendibilidade.

Gering (1999) defende que o CBA permite determinar a rendibilidade dos clientes. Podemos ter organizações focalizadas nos clientes que realizam a segmentação com base nas suas necessidades. O CBA é necessário para realizar uma segmentação e depois estabelecer valor.

Lin et al. (2001) refere que a logística está a ser vista como uma vantagem competitiva. Gestão de logística pode ser definida como o processo da cadeia de abastecimento que planeia, implementa e controla o fluxo efectivo e eficiente, armazena os bens e relaciona a informação desde o ponto de origem até ao ponto de consumo de modo a satisfazer os desejos do cliente.

A função logística que foi sempre considerada com elevados custos é necessária e inevitável num negócio. Com o uso estratégico do CBA, com suporte da gestão, com visão de sucesso da logística, pode tornar-se uma vantagem competitiva.

King et al. (1994) focam vários factores que hoje em dia geram cada vez mais gastos gerais de fabrico: logística e os movimentos de fluxos de trabalho através da empresa; transacções relacionadas com o fornecimento de recursos satisfazendo a procura interna; qualidade das transacções e dos produtos; desenho, planos de trabalho, processos e especificações.

No fundo, no sector do comércio, o objectivo do CBA não será o apuramento do custo do produto, mas existem outras aplicações de enorme interesse.

Observando o mercado encontramos várias empresas no sector do comércio que já utilizam o CBA. Como exemplo existem casos de supermercados que utilizam o CBA para colocar as mercadorias nas prateleiras. É claro que vão colocar a mercadoria mais rentável no local mais visível e mais amplo.

No estudo de Khoury e Anceleviez (1999) no Brasil temos empresas do sector do comércio que utilizam o CBA. 


\title{
5. VIABILIDADE DA IMPLEMENTAÇÃO DO CBA NOS DIVERSOS SECTORES
}

Depois desta análise aos vários sectores verificamos que é viável a implementação do CBA nos diversos sectores. Ou seja, pertencer ao sector da indústria, do comércio ou dos serviços não inviabiliza a aplicação do CBA.

Em suma

\begin{abstract}
"o ambiente competitivo tanto para a indústria como para os serviços temse tornado mais desafiante e exigente. Como consequência, as empresa dos nossos dias necessitam de diferente e melhor informação de contabilidade de gestão." (Atkinson et al., 2001:15)
\end{abstract}

Em Portugal, num estudo realizado por Duarte (2002), temos CBA nas seguintes actividades económicas: telecomunicações, metalomecânica e metalúrgica, química e minerais não metálicos. Também, apurou-se que está a ser implementado nas actividades: dos correios, de distribuição de gás canalizado, de água, electricidade e gás, de transportes, de minas e de material eléctrico de precisão.

Segundo Abrahams e Reavely (1998), o CBA é uma ferramenta utilizada para identificar os custos dos serviços governamentais. Provouse que o CBA é uma ferramenta poderosa no sistema de gestão de desempenho do estado de Iowa, porque fornece informações imprescindíveis acerca dos custos.

"Em suma o CBA é uma aproximação a qual parece ter uma grande aplicabilidade nas diversas actividades económicas, ao longo da cadeia de valor e em relação a um intervalo de objectivos de custo dentro de cada negócio individual.” (Innes e Mitchell, 1998:23)

Innes e Mitchell (1998) observaram três empresas de sectores diferentes: electrónica, engenharia tradicional e retalho. Nos três casos o CBA teve sucesso.

Innes e Mitchell (1998) realizaram um outro estudo no Reino Unido, onde verificaram que duas empresas pertencentes à actividade económica de metais e fundição rejeitaram o CBA, depois deste ter sido implementado. Contudo, tudo indica, que a rejeição foi devido às dimensões das empresas e não ao sector a que pertenciam. Outras actividades económicas que implementaram o CBA no Reino Unido foram: electrónica, engenharia, fabrico de papel e serviços financeiros.

Khoury e Anceleviez (1999) realizaram um estudo no Brasil, onde se verificou que as empresas que utilizam mais o CBA pertencem ao sector da indústria nomeadamente: sectores da química e petroquímica, 
siderurgia e metalurgia, automóveis e peças, alimentação e electrónicas. Nenhuma pertencia ao sector de serviços. A utilização do CBA é recente.

"a probabilidade de uma empresa implementar o sistema CBA não depende do tipo da propriedade da mesma, nem do sector de actividade em que está inserida nem mesmo da sua localização geográfica." (Duarte, 2002:103)

Do estudo que Gomes e Rodrigues (2003) realizaram, concluíram que

"Em suma, podemos dizer que a aplicabilidade do CBA no sector das empresas comerciais é questionada, no sector das empresas de serviços é importante, e, que o sector industrial está numa fase intermédia.

Ao compararmos com o estudo de Innes e Mitchell (1995) verificámos que não existe relação entre as percentagens dos gastos gerais e as rejeições pelas empresas. Tanto as empresas com altas percentagens de gastos gerais como as com baixas percentagens rejeitam o CBA. Só demonstra que não existe um procedimento geral dentro de cada actividade económica. No fundo, as empresas têm comportamentos diversos que dependem da sua cultura, história, do contexto onde estão inseridas, da disponibilidade dos recursos, da competitividade do sector, do tamanho, etc.

Como conclusão final, podemos dizer que a regra "Willie Sutton" é importante para verificar aplicabilidade do CBA, mas não suficiente. Em todos os casos é sempre necessário realizar mais alguns estudos, pois existem outros factores que as empresas consideram mais prementes que o elevado montante de gastos gerais." (Gomes e Rodrigues, 2003:13)

\section{CONCLUSÃO}

O CBA é um método que se baseia nas actividades para efectuar a distribuição de custos. Daí que seja necessário estabelecer uma hierarquia de custos em que classificaremos em: nível unidade, nível lote, nível manutenção da produção, nível manutenção da empresa e nível manutenção cliente. Os custos são afectados às actividades e depois através dos indutores de custo serão imputados aos objectos de custo.

Para que o CBA seja implementado numa empresa têm de verificar-se determinadas condições, tais como: gastos gerais de fabrico elevados, grande diversidade nos produtos/serviços e clientes, empenho da gestão de topo, disponibilidade de meios informáticos, grande competitividade, custos dos erros superior ao custo das medidas.

O CBA apareceu no sector da indústria porque as empresas deste sector tiveram necessidade de aplicar novas técnicas para o apuramento do custo do produto. Contudo, não podemos generalizar e afirmar que o CBA é viável em todas as empresa deste sector, pois, dentro deste existe uma diversidade de actividades económicas. 
Em relação ao sector dos serviços, apurámos a viabilidade do CBA. Apesar deste ter nascido no sector da indústria é no sector dos serviços que encontra um amplo campo de aplicação, devido às características intrínsecas das empresas. Ou seja, são empresas que na sua estrutura de custos têm custos directos ínfimos e, paralelamente, apresentam ao mercado uma diversidade de serviços.

No que respeita ao sector do comércio, o CBA, também, é viável. Apesar dos gastos gerais serem baixos e do custo das mercadorias não ser problemático, existem outros factores a ter em conta. Como por exemplo é imprescindível às empresas deste sector afectarem os custos de logística, de distribuição, de "marketing" aos serviços ou aos clientes, como também, é necessário analisar a rendibilidade dos clientes.

Através de uma revisão da literatura, apurámos que uma grande diversidade de actividades económicas, dos diferentes sectores, já utiliza o CBA.

Em suma, verificámos que é viável a implementação do CBA nos diversos sectores. Ou seja, pertencer ao sector da indústria, do comércio ou dos serviços não inviabiliza a aplicação do CBA.

\section{BIBLIOGRAFIA}

Abrahams, Mark e Reavely, Mary, "Activity based costing: illustrations from the State of Iowa”, Government Finance Review, Abril 1998, pp. 1-10.

Atkinson, Anthony, Banker, Rajiv, Kaplan, Robert e Young, Mark, Management Accounting, Prentice Hall, 2001.

Baxendale, Sidney, "Activity-based costing for the small business: a primer", Business Horizons, 44(1), Janeiro 2001, p.61.

Brimson, James e Antos, John, Activity-based Management for service industries, government entities and nonprofit organization, Wiley Cost Management Series, 1994.

Chan, Yee-Ching Lilian, "Improving hospital cost accounting with activity-based costing”, Health Care Management Review, Vol. 18 (1), Winter 1993, pp. 7178.

Charterd Institute of Managements Accountants(CIMA), "ABC within a service organization", Management Accounting, Vol. 71(11), Dezembro 1993, pp. 4046.

Cobb, I., Innes, J. e Mitchell, F., Activity based costing - problems in practice, CIMA, 1992.

Cooper, Robin, "Cost classification in unit-based and activity-based manufacturing cost systems", Journal of cost management, Summer 1990, pp. 4-14.

Cooper, Robin, "The rise of activity-based costing. Part four: what do activity-based cost systems look like?", Journal of cost management, Spring 1989, pp. 3849. 
Cooper, Robin e Kaplan, Robert, Cost and effect - using integrated cost systems to drive profitability and performance, Harvard Business School Press, 1998.

Cooper, Robin e Kaplan, Robert, "Measure costs right: make the right decisions", Harvard Business Review, Set-Out 1988, pp. 96-103.

Cotton, William, Jackman, Susan e Brown, Richard, "Note on a New Zealand replication of the Innes et al. UK activity-based costing survey", Management Accounting Research, 14(1), Março 2003, pp. 67-72.

Duarte, Paula, ABC - Estado actual de aplicação em Portugal, Dissertação do III Mestrado em Contabilidade e Auditoria, Universidade Aberta, 2002.

Gering, Michael, "Activity based costing and the customer", Management Accounting (British), 77(4), Abril 1999, pp.26.

Gomes, Conceição e Rodrigues, Lúcia, "Apuramento das actividades económicas em que deve ser implementado o CBA”, XV Encontro da ADCES, Leiria, 2003.

Horngren, Charles, Foster, George e Datar, Srikant, Cost Accounting, a managerial emphasis, Prentice Hall, 10ª edição, 2000.

Howell, Robert e Soucy, Stephen, "Cost accounting in the new manufacturing environment”, Strategic Finance, 69(2), Agosto 1987, pp. 42-48.

Innes, J. e Mitchell F., A practical guide to activity-based costing, CIMA, 1998.

Innes, J e Mitchell F., Activity based costing - a review with case studies, CIMA, 1989.

Innes, J. e Norris, G., The Use of Activity-Based Information, A managerial perspective, Chartered Institute of Management Accountants, 1997.

Kaplan, Robert, "Accounting lag: the obsolescence of cost accounting systems", California Management Review, 28(2), Winter 1986, pp. 174-199.

King, M., Lapsley, F., Mitchell, F. e Moyes, J., Activity Based Costing in Hospitals A case study investigation, CMA Publishing, 1994.

Khoury, Carlos e Ancelevicz, Jacob, "A utilização do sistema de custos ABC no Brasil”, Revista de Administração de Empresas, V. 39, Jan.-Mar. 1999, pp. 55-63.

Krupnicki, Michael e Tyson, Thomas, "Using ABC to determine the cost of servicing customers", Management Accounting, Vol. 79(6), Dezembro 1997, pp. 40-46.

Lambert, Don e Whitworth, John, "How ABC can help service organizations", The Management Accounting Magazine, Vol. 70(4), Maio 1996, pp. 24-29.

Lewis, R., "Activity-based costing for marketing", Management Accounting, Novembro 1991, pp. 33-36.

Lin, Binshan, Collins, James e Su, Robert, "Supply chain costing: an activity-based perspective", International Journal of Physical Distribution \& Logistics Management, 31(10), 2001, pp. 702-713.

Lucey,T., Costing, Continuum, 1996.

Mabberley, Julie, Activity-based costing in financial institutions, Prentice Hall, 1998.

Maher, Michael, Stichney, Clyde e Weil, Roman, Managerial Accounting - an introduction to concepts, methods and uses, Dryden Press, 1997.

Plossl, George, "Cost accounting in manufacturing: dawn of a new era", Production Planning \& Control, 1(1), 1990, pp. 61-68.

Rotch, William, "Activity-based costing in service industries", Journal of Cost Management, Summer 1990, pp. 4-14.

Sá, Patrícia e Jorge, Susana, "O custeio baseado nas actividades (CBA) como ferramenta de gestão estratégica de custos: o papel do CBA na quantificação dos custos da qualidade", VII Jornadas de Contabilidade e auditoria, 1998.

Shapiro, Jeremy, "On the connections among activity-based costing, mathematical programming models analyzing strategic decisions, and the resource-based 
view of the firm", European Journal of Operational Research, 118, 1999, pp. 295-314.

Silva, Fernando G Gonçalves, Contabilidade Industrial, Livraria sá da costa editora, 1991.

Sutton, Sharon, "A new age of accounting”, Production and Inventory Management Journal, 32(1), First quarter 1991, pp. 72-74.

Vieira, Rui, Accounting and change in the financial services actor: the case of activity-based costing in a Portuguese bank, Tese de doutoramento, University of Warwick, Setembro 2002.

Vokurka, Robert e Lummus, Rhonda, "At what overhead levels does activity-based costing pay off?”, Production \& Inventory Management Journal, 42 (1), Winter 2001, pp. 40-49. 